University of Nebraska - Lincoln

DigitalCommons@University of Nebraska - Lincoln

U.S. Environmental Protection Agency Papers

U.S. Environmental Protection Agency

2007

Valuing water quality improvements in the United States using meta-analysis: Is the glass half-full or half-empty for national policy analysis?

\author{
George Van Houtven \\ RTI International, 3040 Cornwallis Road, P.O. Box 12194, Research Triangle Park, NC 27709-2194, United \\ States \\ John Powers \\ U.S. Environmental Protection Agency, 1200 Pennsylvania Ave., NW, Washington, DC 20460, United States \\ Subhrendu K. Pattanayak \\ RTI International, 3040 Cornwallis Road, P.O. Box 12194, Research Triangle Park, NC 27709-2194, United \\ States
}

Follow this and additional works at: https://digitalcommons.unl.edu/usepapapers

Part of the Civil and Environmental Engineering Commons

Van Houtven, George; Powers, John; and Pattanayak, Subhrendu K., "Valuing water quality improvements in the United States using meta-analysis: Is the glass half-full or half-empty for national policy analysis?" (2007). U.S. Environmental Protection Agency Papers. 11.

https://digitalcommons.unl.edu/usepapapers/11

This Article is brought to you for free and open access by the U.S. Environmental Protection Agency at DigitalCommons@University of Nebraska - Lincoln. It has been accepted for inclusion in U.S. Environmental Protection Agency Papers by an authorized administrator of DigitalCommons@University of Nebraska - Lincoln. 


\title{
Valuing water quality improvements in the United States using meta-analysis: Is the glass half-full or half-empty for national policy analysis?
}

\author{
George Van Houtven ${ }^{\mathrm{a}, *}$, John Powers ${ }^{\mathrm{b}}$, Subhrendu K. Pattanayak ${ }^{\mathrm{a}}$ \\ ${ }^{a}$ RTI International, 3040 Cornwallis Road, P.O. Box 12194, Research Triangle Park, NC 27709-2194, United States \\ ${ }^{\mathrm{b}}$ U.S. Environmental Protection Agency, 1200 Pennsylvania Ave., NW, Washington, DC 20460, United States
}

Received 1 October 2005; received in revised form 22 November 2006; accepted 21 December 2006

Available online 20 February 2007

\begin{abstract}
The literature estimating the economic value for water quality changes has grown considerably over the last 30 years, resulting in an expanded pool of information potentially available to support national and regional policy analysis. Using 131 willingness to pay estimates from 18 studies that use a similar definition of water quality, we performed a meta-regression analysis and found mixed results. We find that WTP varies in systematic and expected ways with respect to factors such as the size of the water quality changes, average household income, and use/nonuse characteristics of respondents. As a whole, we conclude that our metaregression results provide a reasonable basis for estimating expected WTP values for defined changes in water quality. However, despite a large number of existing economic valuation studies, relatively few could be meaningfully combined through meta-analysis due to heterogeneity in the commodities being valued in the original studies. Based on these findings, we provide recommendations for future research, including suggestions regarding more standardized approaches for defining water quality and reporting information in valuation studies.
\end{abstract}

(C) 2007 Elsevier B.V. All rights reserved.

JEL classification : Q2

Keywords: Water quality valuation; Meta-analysis; Meta-regression analysis; Benefit transfer

\section{Introduction}

Protecting and improving water quality in the U.S. has been a focal point of national environmental policy for over 30 years, particularly since the passage of the Clean Water Act

\footnotetext{
* Corresponding author. Tel.: +1 9195417150.

E-mail address: gvh@rti.org (G. Van Houtven).
} 
(CWA) in 1972. The overall goal of the CWA is to "... restore and maintain the chemical, physical, and biological integrity of the Nation's waters." Although much has been accomplished toward achieving this goal, policy makers continue to face the challenge of setting priorities and implementing effective and efficient clean water programs. Evaluating the social welfare implications of environmental policy options - now often required by executive order or statute has proven to be particularly challenging. However, recent efforts by federal agencies and research organizations to synthesize and integrate the various natural, physical, and social sciences used in such evaluations are beginning to show tangible progress (see, for example, NRC/NAS, 2005).

In light of these challenges, this paper provides an assessment of the existing literature on the economic value ("benefits") of improvements in surface water quality. In particular, the purpose of this research is to determine the usefulness of the literature for supporting environmental benefit assessments and policymaking at the national level. Our approach involves two basic questions: First, can we estimate a regression function(s) that represents societal preferences for water quality contained in a collection of existing (primary) studies, which can then be used for benefit transfer? Second, in what ways can the literature be augmented or adapted in the future to best address the needs of national policy analysis?

We find that the existing body of research provides a potentially rich and diverse source of secondary data for evaluating national water policy; however, this diversity presents both opportunities and obstacles for benefit transfer. In practice, relatively few existing studies have been actively used in benefit transfers to evaluate the benefits of national water quality policies. One reason is that few of these studies are national in scope, and extrapolating values beyond the spatial boundaries of a study area inevitably adds to uncertainty.

Another specific challenge in using the existing literature for national analysis is that, across valuation studies, water quality is defined in a number of different ways. ${ }^{1}$ In many cases it is difficult to match these definitions with those used to predict policy-related water quality changes. For example, two alternative paradigms provide a useful illustration of the potential for heterogeneity across the literature. One approach involves estimating the willingness to pay for reductions in one or more specific pollutants (e.g., Bockstael et al., 1987), which can be viewed as inputs in an ecosystem production function. The other approach involves estimating willingness to pay for enhancements to ecosystem services (e.g., suitable for swimming (Carson and Mitchell, 1993) or fish become safe to eat (Viscusi et al., 2004)), which can be viewed as outputs of an ecosystem production function.

To quantitatively evaluate results from this literature, we use meta-analysis. This approach allows us to synthesize information from selected studies in a systematic way and to test hypotheses regarding the determinants of these estimates. It also allows us to explore a format for predicting values, which is a critical component of any benefit transfer method. Although it has evolved primarily in health sciences research, meta-analysis is increasingly being applied in economics (Stanley, 2001), including nonmarket valuation research (Smith and Pattanayak, 2002). Recently, Johnston et al. (2003, 2005) also conducted meta-analyses involving value

\footnotetext{
${ }^{1}$ This problem of commodity heterogeneity is not unique to water quality. In fact, it appears to be the norm in the environmental valuation literature, making synthesis, meta-analysis, and benefit transfer difficult. See, for example, McConnell and Walls (2005; open space), Poe et al. (2001; groundwater), Woodward and Wui (2001; wetlands), Boyer and Polasky (2004; urban wetlands), Nunes et al. (2001; biodiversity), and Loomis and White (1996; threatened and endangered species).
} 
estimates for surface water quality improvements. Although similar in several respects to our analysis, the two meta-analyses focus on water quality changes that specifically involve improvements in fish habitat and Johnston et al. (2003) focuses mainly on nonuse value estimates.

For our analysis, we identified and reviewed over 300 publications related to water quality valuation; however, we selected values from a subset of these studies that were sufficiently comparable for inclusion in a meta-analysis. To maintain comparability, we limited the metaanalysis to stated preference studies conducted in the U.S. and to studies that described water quality in terms that could be converted to a common 10-point scale.

Our investigation provides both good and bad news for policy analysis and benefit transfer. On one hand, we find that WTP varies in systematic and expected ways with respect to factors such as the size of the water quality changes, average household income, and use/nonuse characteristics of respondents. These results show promise for benefit transfer because they suggest that it may be possible to reliably predict WTP for appropriately selected changes in water quality. On the other hand, despite the large number of existing economic valuation studies, relatively few could be meaningfully combined through meta-analysis. The main obstacle to including more valuation results is the heterogeneity in water quality descriptions across studies, making it difficult to convert findings to a common scale for analysis. As a result, information from a large number of studies could not be synthesized for use in policy analysis. In addition, although the meta-analysis results provide a reasonable basis for predicting WTP for broad water quality changes, they are more limited for explaining how the characteristics of the affected population and the spatial variation in water quality changes affect WTP.

Based on our review and analysis, we provide recommendations for future research that may enhance the utility of the literature for national policy analysis. One of the main challenges is developing definitions and characterizations of water quality changes that are both policyrelevant and easily communicated and replicated across studies. We argue that the "designated use" classifications, which are widely used to establish water quality standards across the country, provide a particularly useful framework for standardization.

\section{Overview of empirical water quality valuation research}

To comprehensively evaluate the existing body of empirical water quality valuation research and its applicability for assessing national water pollution control policies, we began by identifying as many primary empirical studies as possible. In 2002 and 2003, we conducted extensive literature searches using several literature databases and search engines, ${ }^{2}$ and we identified additional candidate studies by scanning the reference lists from acquired studies.

In screening and selecting studies for additional analysis, we focused on empirical studies that used primary data and used nonmarket valuation methods to estimate economic values for defined changes in surface water quality for freshwater and saltwater bodies in the United States. Studies addressing only groundwater or tap water quality were excluded, as were studies addressing only water quantity issues. We included peer-reviewed publications from journals and

\footnotetext{
${ }^{2}$ These searches included the Environmental Valuation Reference Inventory (EVRI) (http://199.212.18.90/evri), the Beneficial Use Values Database (BUVD (http://buvd.ucdavis.edu/index.htm), ENVALUE (http://www2.epa.nsw.gov.au/ envalue), ingenta, AGRICOLA (Agricultural Online Access) (http://www.nal.usda.gov/ag98), and ECONLIT.
} 
books, as well as articles from the grey literature (working papers, presentations, Master's theses, and $\mathrm{PhD}$ dissertations).

Based on these criteria, we identified 90 publications published between 1968 and 2002. Many of these publications can be grouped with others as part of a common study (58 studies in all). We then created a database of water quality value estimates by extracting information reported in these studies. A total of 1014 value estimates are included in this database and each value is characterized in various dimensions, including type of value, type of water quality change, type of water resource, type of valuation methods used, and characteristics of the population studied. ${ }^{3}$ To distinguish between numbers of studies, publications, and value estimates, we use the notation $N_{\mathrm{s}}, N_{\mathrm{p}}$, and $N_{\mathrm{v}}$, respectively, in Table 1 , and in the remainder of the paper.

By summarizing some of the key characteristics of the publications and value estimates included in this database, Table 1 provides an overview of the existing empirical water quality valuation in the United States. The evidence from our literature search indicates that the rate at which studies are being conducted and published has increased steadily since the late 1960s, and a large number of them - 60 publications in our database - have been published in peerreviewed outlets.

The geographic coverage of existing research is broad, but there are gaps worth noting. For example, a large portion of available value estimates ( 74 percent) are focused on water quality changes at a local (sub-state) level. Although individuals are certain to place more value on improvements in local water resources than on more distant waters, there is still relatively little evidence about how distance to water systematically affects these values. Also, the geographic distribution of values is relatively uneven, with roughly one-half of the available values estimated for waters in the South region and less than 2 percent estimated for waters in the West. By comparison, the available value estimates are rather evenly distributed across different types of water resources. Roughly three-quarters of the value estimates are for freshwater bodies (rivers, stream, lakes, reservoirs, etc.) and the remainder for saltwater bodies (estuaries and coastal waters).

The nonmarket valuation methods most commonly used to generate these value estimates generally fall into one of three categories - stated preference, travel cost, or hedonic property value. Travel cost studies related to water-based recreation provide the highest number of value estimates (74 percent) in the database. Stated preference methods, in particular contingent valuation, produced 21 percent of the value estimates. Hedonic methods provided 6 percent of the value estimates.

The measures used to describe and evaluate water quality changes are among the most heterogeneous aspects of the water quality valuation research compiled in our database. Due in large part to the stated goals in the CWA of achieving fishable/swimmable waters in the United States and following a precedent established by some of the earlier valuation studies (Mitchell and Carson, 1986; Desvousges et al., 1987), stated preference studies often define water quality in terms of their suitability for, or ability to support, specific recreational activities-e.g., boatable, fishable, and/or swimmable water quality. About 24 percent of the value estimates in the database describe water quality in these general terms. Subjective ratings such as Likert scales or poor/fair/good/excellent classifications are also used in stated preference studies, but these

\footnotetext{
${ }^{3}$ Since compiling this database for our analysis, we have identified a limited number of more recently published water quality valuation studies. However, none of these studies provide value estimates that meet our criteria for inclusion in the meta-analysis.
} 
Table 1

Summary statistics for U.S. water quality valuation studies

\begin{tabular}{|c|c|c|c|c|}
\hline & \multicolumn{2}{|c|}{ Publications $\left(N_{\mathrm{p}}=90\right)$} & \multicolumn{2}{|c|}{ Value estimates $\left(N_{\mathrm{v}}=1014\right)$} \\
\hline & Number & Percent & Number & Percent \\
\hline \multicolumn{5}{|l|}{ Type of publication } \\
\hline Peer-reviewed journal/book & 59 & 66 & 646 & 64 \\
\hline $\mathrm{PhD} /$ Master's thesis & 8 & 9 & 128 & 13 \\
\hline Other (working paper, report, etc.) & 23 & 26 & 240 & 24 \\
\hline \multicolumn{5}{|l|}{ Year of publication } \\
\hline Before 1980 & 7 & 8 & 28 & 3 \\
\hline 1980-1989 & 21 & 23 & 324 & 32 \\
\hline 1990-1999 & 40 & 44 & 448 & 44 \\
\hline 2000 or later & 22 & 24 & 214 & 21 \\
\hline \multicolumn{5}{|l|}{ Type of water resource affected } \\
\hline Freshwater (lakes, rivers, streams, etc.) & 69 & 77 & 752 & 74 \\
\hline Saltwater (estuaries, coastal waters, etc.) & 26 & 29 & 330 & 33 \\
\hline \multicolumn{5}{|l|}{ Geographic extent of WQ change } \\
\hline National & 3 & 3 & 12 & 1 \\
\hline Multistate & 8 & 9 & 60 & 6 \\
\hline Single state & 21 & 23 & 194 & 19 \\
\hline Local & 62 & 69 & 748 & 74 \\
\hline \multicolumn{5}{|l|}{ Regions experiencing WQ change } \\
\hline National & 3 & 3 & 12 & 1 \\
\hline Northeast & 30 & 33 & 204 & 20 \\
\hline South & 30 & 33 & 504 & 50 \\
\hline Midwest & 31 & 34 & 281 & 28 \\
\hline West & 3 & 3 & 13 & 1 \\
\hline \multicolumn{5}{|l|}{ Valuation method used } \\
\hline Stated preference & 34 & 38 & 214 & 21 \\
\hline Travel cost and contingent behavior & 53 & 59 & 749 & 74 \\
\hline Hedonic property value & 10 & 11 & 57 & 6 \\
\hline \multicolumn{5}{|l|}{ WQ descriptor/indicator used } \\
\hline Recreation support (e.g., boatable/fishable/swimmable) & 16 & 18 & 246 & 24 \\
\hline Rating scale (e.g., poor/fair/good/excellent) & 8 & 9 & 45 & 4 \\
\hline Pollutant concentration & 34 & 38 & 520 & 51 \\
\hline Secchi depth (for water clarity) & 7 & 8 & 63 & 6 \\
\hline Fish consumption advisory & 9 & 10 & 31 & 3 \\
\hline
\end{tabular}

represent less than 5 percent of all the value estimates in the database. Generally speaking, revealed preference studies rely on more specific indicators of water quality, with the expectation that these indicators are directly related to the water quality services that individuals perceive and value. For example, a large number of studies measure revealed preferences in relation to pollutant concentrations and/or regulatory thresholds such as ambient water quality criteria (AWQCs) or fish consumption advisories.

\section{Data selection for meta-analysis}

The results summarized in Table 1 provide a useful overview and synthesis of water quality valuation research in the U.S.; however, the primary objective in compiling this database of water 
quality values was to determine whether these estimates could be systematically combined in a common analytical framework. To most effectively analyze these data, it was necessary to confront an inherent problem in meta-analysis - the tradeoff between expanding the metasample to improve statistical estimation and reducing the sample to ensure comparability across studies. To strike an appropriate balance, we used the following criteria to select studies for our meta-sample.

First, it was essential to identify value estimates for water quality changes that can be expressed in comparable terms. Therefore, as described in more detail below, we selected studies that could be linked to a commonly defined water quality metric.

Second, it was also advantageous to select estimates derived from similar valuation methods because it ensures a common value concept in the analysis. For this reason, we focused specifically on values estimated with stated preference methods. Although we identified other potentially convertible values estimated using travel cost methods (TCMs), we decided not to include them in this meta-analysis for three reasons. First, statistical tests of pooling the two data groups into a common regression tended to reject equality of the parameters across groups. Second, a large majority of the TCM values came from the same study (Smith and Desvousges, 1986), meaning that it was difficult to distinguish whether differences in parameter estimates were due to differences in, for example, the valuation method or to unobservable differences associated with the particular study. Third, the value measures from TCM and CV are fundamentally different (i.e., Marshallian consumer surplus versus Hicksian compensating surplus); therefore, pooling these data might introduce conceptual inconsistencies. Smith and Pattanayak (2002) suggest "structural meta-analysis" as a way of combining estimates from different valuation approaches in theoretically consistent manner. However, this structural approach, which often requires multiple nonlinear equations linked to a common preference structure, is beyond the scope of this study and, to our knowledge, has not yet been fully applied or demonstrated in the literature.

Based on these criteria, we identified and selected 131 value estimates from the literature to include in the meta-analysis. These estimates are drawn from 21 publications (18 studies) produced between 1977 and 2003, which are summarized in Table 2.

\section{Determinants of WTP for water quality improvements}

Eq. (1) broadly defines a "variation", or WTP function with respect to changes in water quality from $Q^{0}$ to $Q^{1}$.

$$
\mathrm{WTP}=V\left(Q^{0}, Q^{1}, P, Y ; B\right)
$$

The properties of this function, as described by McConnell (1990) and further explored by Whitehead (1995), provide a conceptual guide for constructing and estimating a meta-regression function of water quality values. This function also provides the basic conceptual foundation for constructing a benefit transfer function, which can be used to predict values for defined changes in water quality.

According to Eq. (1), the determinants of water quality value estimates can be grouped by: (1) the characteristics of the water quality "commodity" $(Q)$ and (2) characteristics of the study population, including income $(Y)$ and other socio-demographic variables $(B)$ and price $(P)$ effects. In addition, the valuation approach used to estimate WTP and other study-specific characteristics can have an effect on the resulting value estimates. 
Table 2

Summary of publications and value estimates included in meta-analysis $\left(N_{\mathrm{p}}=21, N_{\mathrm{s}}=18, N_{\mathrm{v}}=131\right)$

\begin{tabular}{|c|c|c|c|c|c|}
\hline $\begin{array}{l}\text { Study } \\
\text { cluster }\end{array}$ & Publication name & Geographic focus & $\begin{array}{l}\text { Resource } \\
\text { type }\end{array}$ & Water quality change evaluated & $\begin{array}{l}\text { Mean (number) } \\
\text { of WTP } \\
\text { estimates }^{\text {a }}\end{array}$ \\
\hline 1 & $\begin{array}{l}\text { Carson and Mitchell } \\
\text { (1993) }\end{array}$ & Nationwide & $\begin{array}{l}\text { Rivers, } \\
\text { lakes }\end{array}$ & $\begin{array}{l}\text { (a) Avoid reduction to below-boatable levels, (b) improve from } \\
\text { boatable to fishable, and (c) improve from fishable to swimmable }\end{array}$ & $\$ 168(3)$ \\
\hline 2 & Croke et al. (1986) & Chicago metropolitan area & River & $\begin{array}{l}\text { Improve to allow for: (a) outings along the banks of a river, } \\
\text { (b) boating and outings, and (c) fishing, boating, and outings }\end{array}$ & $\$ 88(6)$ \\
\hline 3 & $\begin{array}{l}\text { Desvousges et al. } \\
(1987)\end{array}$ & Monongahela River, PA & River & $\begin{array}{l}\text { (a) Avoid reduction to below-boatable levels, (b) improve from } \\
\text { boatable to fishable, and (c) improve from fishable to swimmable }\end{array}$ & $\$ 55(24)$ \\
\hline 4 & $\begin{array}{l}\text { Farber and Griner } \\
(2000)\end{array}$ & $\begin{array}{l}\text { Loyalhanna Creek, } \\
\text { Conemaugh River, PA }\end{array}$ & River & $\begin{array}{l}\text { Improve from: (a) severely polluted to unpolluted, (b) severely } \\
\text { polluted to moderately polluted, and (c) moderately polluted to } \\
\text { unpolluted }\end{array}$ & $\$ 62(10)$ \\
\hline 5 & Gramlich (1977) & $\begin{array}{l}\text { Charles River, Boston, MA, } \\
\text { and nationwide }\end{array}$ & River & $\begin{array}{l}\text { Improve from } 1973 \text { status quo to a level of "clean enough for } \\
\text { swimming and wildlife" for: (a) rivers nationwide and (b) } \\
\text { Charles River }\end{array}$ & $\$ 167(2)$ \\
\hline 6 & Walsh et al. (1978) & South Platte River Basin, CO & River & Avoid reduction in 3-point index & $\$ 156(6)$ \\
\hline 7 & Lant and Roberts (1990) & Rivers in Iowa and Illinois & River & $\begin{array}{l}\text { Improve from: (a) poor to fair, (b) fair to good, and (c) good } \\
\text { to excellent }\end{array}$ & $\$ 61(6)$ \\
\hline 7 & Lant and Tobin (1989) & Rivers in Iowa and Illinois & River & $\begin{array}{l}\text { Improve from: (a) poor to fair, (b) fair to good, and (c) good } \\
\text { to excellent }\end{array}$ & $\$ 110(9)$ \\
\hline 8 & Nowak et al. (1990) & Milwaukee, WI & River, lake & Improve to fishable/swimmable & $\$ 87(14)$ \\
\hline 8 & Nowak et al. (1989) & West Bend, WI & River, lake & Improve to excellent/good & $\$ 26(1)$ \\
\hline 9 & Azevedo et al. (2001) & Clear Lake, IA & Lake & $\begin{array}{l}\text { Five scenarios with multiple water quality indicators: clarity, } \\
\text { frequency of algae blooms, color, odor, frequency of swimming } \\
\text { advisories, fish species diversity }\end{array}$ & $\$ 69(5)$ \\
\hline 10 & Cronin (1982) & Potomac River, Washington, DC & River & $\begin{array}{l}\text { Improvement on 5-level index describing } 6 \text { water quality attributes } \\
\text { (suitability for swimming, suitability for boating, fish habitat, odor, } \\
\text { appearance, ecology) }\end{array}$ & $\$ 41(8)$ \\
\hline 11 & Johnston et al. (1999) & Wood-Pawcatuck Watershed, RI & River, lake & Improve one unit on 10 -point index & $\$ 124(2)$ \\
\hline 12 & Edwards (1984) & Rhode Island Salt Ponds & Estuary & $\begin{array}{l}\text { (a) Avoid reduction from swimmable to boatable, (b) avoid } \\
\text { reduction from swimmable to unusable for recreation, and (c) } \\
\text { an improvement from swimmable to shellfishable }\end{array}$ & $\$ 60(6)$ \\
\hline 13 & $\begin{array}{l}\text { Binkley and Hanemann } \\
(1978)\end{array}$ & Boston-Cape Cod area beaches & $\begin{array}{l}\text { Fresh and } \\
\text { saltwater }\end{array}$ & $\begin{array}{l}\text { (a) Reduced to ranking of } 1 \text { on a scale of } 1-5 \text { and (b) improved } \\
\text { to a ranking of } 5 \text { on a scale of } 1-5\end{array}$ & $\$ 149(2)$ \\
\hline
\end{tabular}


Hayes et al. (1992)

Kaoru (1993)

17 Wey (1990)

18

Lipton (2003)
Chesapeake Bay area

Upper Narragansett Bay,

Rhode Island

Upper Narragansett Bay,

Rhode Island

Martha's Vineyard, Massachusetts Estuary

Great Salt Pond, Block Island, RI Estuary

Chesapeake Bay
Estuary

Estuary

Estuary

Estuary
Improvement from "unacceptable for swimming" to "acceptable"

$\$ 76(2)$

Programs that achieve WQ that is a) Safe for swimming b) Suitable

$\$ 62(16)$

for shellfishing

Programs that achieve WQ that is: (a) safe for swimming and (b)

suitable for shellfishing

Raise the WQ in 3 ponds so that they would be open for shellfishing \$182 (1) year round

(a) Improvement in 6-point index of perceived water quality and (b) $\$ 32$ (1) restrictions on access

Marginal change on a 4-point scale: very good, good, fair, and poor $\quad \$ 77(5)$

TOTAL: 


\subsection{The water quality "commodity"}

In Eq. (1), the commodity to be valued is defined simply as the change in water quality $\left(Q^{1}-\right.$ $Q^{0}$ ). In practice, however, this commodity is inherently complex and, as shown in Table 1, can be characterized in several dimensions.

To convert the specified water quality changes into a common metric, we constructed a 10point water quality index, $\mathrm{WQI}_{10}$. This index is based in part on the water quality ladder (WQL) developed by Vaughan (1986) as a way of conveying water quality to the lay public, particularly survey respondents. ${ }^{4}$ Vaughan defined the ladder such that, for example, a water quality index value of 2.5 (out of 10) was "boatable", 5.1 was "fishable", and 7.0 was "swimmable". Subsequently, Mitchell and Carson (1986) and others (e.g., Desvousges et al., 1987) have used Vaughan's WQL to obtain willingness to pay estimates for changes in the "steps" of the ladder. 5

This approach to defining water quality combines features of "class-based" and "use-based" methods used by EPA and states to establish water quality standards. A typical class-based description of water quality maps a set of pollutants and their concentrations to a linear scale used to define general water quality according to several quality levels (e.g., Class I, Class II, Class III, etc.). ${ }^{6}$ This approach is simple, but the mapping of pollutants to quality levels is nonspecific, and generally downplays the importance of certain pollutants to certain uses (services). A use-based description of water quality addresses this issue directly, by mapping specific pollutants to specific uses. ${ }^{7}$ For example, pathogens and fecal coliforms are associated with human health exposure from swimming (primary contact recreation), mercury and PCBs are associated with human health exposure from fish consumption, and nutrients (nitrogen and phosphorous) are associated with the overall health of an aquatic ecosystem and the abundance of fish.

By combining the two approaches, the $\mathrm{WQI}_{10}$ combines the simplicity of the class-based approach with its use-specific quality steps, and it provides a basis for linking in-stream chemical, physical, and biological characteristics to human-based economic value estimates. Because the general public (and the typical survey respondent) lacks the technical expertise required to interpret the significance of these ecosystem attributes to services that people value, this linear quality scale and use-specific levels provides a means for defining water quality in broadly understandable terms. From a policy analyst's perspective, this approach is particularly valuable because it provides a consistent basis for relating water quality changes to the Clean Water Act's "fishable-swimmable" goals, and has formed the conceptual foundation for research and policymaking for over 30 years. As a result, it is the definition of water quality that is most commonly used in the stated preference literature, and thus provides the best opportunity for estimating a meta-regression function. ${ }^{8}$

\footnotetext{
${ }^{4}$ In addition, the ladder was linked to McClelland's (1974) National Sanitation Foundation water quality index, which incorporates nine indicators of water quality into a single 10-point index. The indicators include: biological oxygen demand (BOD), dissolved oxygen (DO), fecal coliforms (FC), nitrogen (N), phosphorous (P), total suspended solids (TSS), turbidity, pH, and temperature. See http://www.nsf.org/consumer/earth_day/wqi.asp for a more recent description of the NSF WQI.

${ }^{5}$ For examples of regulatory analyses in which this approach was used, see: http://www.epa.gov/waterscience/guide/ construction/C\&D_econ_proposed.pdf and http://www.epa.gov/npdes/pubs/cafo_natl_ecobenefit_p1.pdf.

${ }^{6}$ For example, see Connecticut's water quality standards at http://dep.state.ct.us/wtr/wq/wqs.pdf.

${ }^{7}$ For example, see Ohio's water quality standards at http://www.epa.state.oh.us/dsw/wqs/wqs.html.

${ }^{8}$ Note that it is increasingly common for researchers and policy-makers to use a use-based definition of water quality. See Viscusi et al. (2004) for an example.
} 
In selecting water quality value estimates from the literature, we identified and included estimates for water quality changes that were described using comparable recreational support descriptions. These descriptions were mapped to the $\mathrm{WQI}_{10}$ scale using the Vaughan mapping described above. We also identified and included value estimates for water quality changes that were described using categorical or ordinal rating scales (e.g., a 5-point Likert scale of water quality or poor/fair/good/excellent water quality categorization). Each of these measures was rescaled to fit a 10-point index. ${ }^{9}$ Although every attempt was made to use a consistent set of criteria for converting these measures and descriptions to the $\mathrm{WQI}_{10}$, the process of converting diverse characterizations of water quality to a single metric inevitably required subjective judgments and involved uncertainty. Table 2 provides summary descriptions of how water quality changes were characterized in each publication. The last column includes the number and average value of the WTP estimates drawn from each publication.

Definitions of relevant water quality changes are further complicated by spatial (and temporal) variations in water quality. For example, both baseline and changes in water quality may vary considerably from one waterbody to another, and this spatial pattern may influence WTP. Preferences for water quality changes may also be influenced by other characteristics of surface waters, including the type and location of the resource.

\subsection{Study population characteristics and prices}

Individual values for water quality changes should reflect both their willingness and their ability to pay. Willingness to pay relates primarily to individuals' preferences, which are determined at least in part by personal characteristics. In particular, individuals who are active recreational users of water resources are also likely to have stronger preferences for improving freshwater quality. Thus, we would expect users to also place higher values on water quality changes than nonusers, all else equal.

The economic conditions that affect an individual's perceived ability to pay for water quality changes can be captured (at least in part) through personal or household income. If water quality is a normal good, then income is expected to have a positive effect on WTP. Similar to scope effects in meta-analysis, the finding of a positive income effect provides evidence of theoretical consistency across nonmarket value estimates (Poe et al., 2001). However, higher income may also entail a higher opportunity cost of time for travel to surface water sites, which may create a countervailing price effect, whereby increases in income have a partially dampening effect on WTP for use-related water quality improvements.

\subsection{Valuation method}

The magnitude of the value estimates for water quality changes is also expected to depend on the way in which the estimates are derived. All of the WTP estimates included in our analysis are based on SP methods (either the contingent valuation method [CVM] or conjoint analysis). Even so, a number of methodological differences have the potential to influence WTP.

One potentially significant difference is the type of value elicitation format used-open-ended (OE) or dichotomous choice (DC). Carson (2000), for example, argues in favor of the DC format

\footnotetext{
${ }^{9}$ A similar approach was used by Johnston et al. (2003) to define a common metric of water quality across multiple studies.
} 
based on findings that individuals will tend to understate their WTP with the OE format because respondents do not have the incentive and are not accustomed to conditions where they have to "find" their maximum point. However, if respondents are answering questions strategically (e.g., as free riders), OE responses may overstate or understate WTP (Smith, 2000). The expected direction of this effect is indeterminate, but meta-analysis offers an approach for testing whether systematic differences exist between DC- and OE-based estimates of water quality values. ${ }^{10}$

WTP may also be influenced by whether the SP survey is conducted in person, over the phone, through a mailed questionnaire, or in another format. It is difficult to specify strong priors for how differences in these methods will affect WTP, though-in-person surveys may allow for more carefully considered responses on the part of respondents, which may reduce upward bias in WTP, but they may also encourage yea-saying on the part of respondents, which would have the opposite effect.

\subsection{Other study characteristics}

WTP estimates may also be influenced by the overall quality of the methods and results of the study. Two potential indicators of study quality are the survey response rate and the publication outlet. Higher response rates and publication in peer-reviewed outlets are generally considered to reflect better quality studies. However, the publication selection process may result in estimation bias if, for example, reviewers and editors are more inclined to accept higher value estimates or if analysts are less likely to submit lower estimates (Stanley, 2001). Thus, while the expected effect of these characteristics on WTP is indeterminate, it is important to control for them in meta-analysis. In a recent review of meta-analyses in nonmarket valuation, Rosenberger and Stanley (2006) find that, in most of the studies they review, publication has a negative effect on valuation estimates.

\section{Data summary}

As described above, our main criteria for selecting value estimates from the literature to include in the meta-analysis were that: (1) they were estimated using stated preference methods, (2) they focused on water quality changes in the U.S., and (3) the water quality commodity being valued could be converted to the 10-point linear scale. Based on these criteria, we selected 131 value estimates from the 18 studies described in Table 2.

Table 3 lists and describes the main variables used in the meta-analysis. Table 4 provides summary statistics for each of these variables. The two primary variables of interest are WTP2000, which is the estimated mean household/individual WTP for a defined change in water quality (converted to 2000 dollars using the consumer price index), and $\mathrm{WQI}_{10} \mathrm{CHANGE}$, which captures the corresponding change in water quality in terms of the $\mathrm{WQI}_{10}$. WTP2000 varies from $\$ 4$ to $\$ 336$ $($ mean $=\$ 83)$ and $\mathrm{WQI}_{10} \mathrm{CHANGE}$ varies from 1 to 8.9 units, with a mean of 3.4 units, such that the average value per unit of water quality change varies from $\$ 2.6$ to $\$ 155$, with a mean of $\$ 30.6$.

The variables $\mathrm{WQI}_{10} \mathrm{BASE}$ and WQ_REC_USE were included to further characterize the water quality changes corresponding to each estimate. $\mathrm{WQI}_{10} \mathrm{BASE}$ defines the level from which water quality is described to improve. The dummy variable WQ_REC_USE equals 1 if the survey's description of water quality change includes a reference to specific recreational

\footnotetext{
${ }^{10}$ In a meta-analysis of groundwater valuation studies, Poe et al. (2001), for example, find a positive and significant effect for values estimated using a DC format.
} 
Table 3

Meta-analysis variable descriptions

\begin{tabular}{ll}
\hline Variable & Description \\
\hline WTP2000 & Annual WTP for water quality change (in 2000 dollars) \\
WQI ${ }_{10} C H A N G E$ & Water quality change (10-point WQI) \\
WQ_REC_USE & $=1$ if the water quality change described in the study includes a reference to \\
& recreational use support (e.g., suitable for recreational fishing) \\
WQI 10 BASE & Baseline level of water quality from which water quality improves \\
ESTUARY & $=1$ if the water quality change occurs in an estuary \\
LOCAL_FWATER & $=1$ if the water quality change is restricted to freshwater in the local area \\
& (i.e., within a single waterbody, county, or metro area) \\
MIDWEST & $=1$ if the affected waterbodies are in the Midwest region of the U.S. \\
SOUTH & $=1$ if the affected waterbodies are in the Southern region of the U.S. \\
INCOME2000 & Average household income (in thousands of 2000 dollars) \\
INCOME_APPROX & $=1$ if average household income was not reported in study (approximated based on \\
PERCENT_USER & local Census data) \\
PUBLISHED & Percent of the sample population that are users of the affected water resource \\
OPEN_ENDED & $=1$ if value is published in a peer-reviewed book or journal \\
RESPONSE_RATE & $=1$ if the value was estimated from an OE valuation question \\
IN_PERSON & Response rate for the survey used in the study (\%) \\
STUDY_YR73 & $=1$ if the survey used in the study was administered with an in-person interview \\
NUM_PERSON & $=$ Year SP survey was fielded (minus 1973) \\
\hline
\end{tabular}

activities that would be supported with improved water quality (e.g., "from boatable to fishable" in Carson and Mitchell, 1993) then WQ_REC_USE equals 1. Roughly two-thirds of the estimates fall into this category.

The dummy variable LOCAL_FWATER identifies water quality changes affecting only local (i.e., those within a metropolitan area or a small portion of a state) freshwater bodies, which applies to 43 percent of the value estimates. Including this variable in the meta-analysis provides

Table 4

Summary statistics for meta-regression variables $\left(N_{\mathrm{v}}=131\right)$

\begin{tabular}{|c|c|c|c|c|c|}
\hline Variables & Mean & Standard deviation & Min & Median & Max \\
\hline WTP2000 & 82.77 & 57.81 & 4.0 & 67.9 & 336.4 \\
\hline$W Q I_{10} C H A N G E$ & 3.39 & 1.93 & 1 & 2.5 & 8.9 \\
\hline$W Q \_R E C \_U S E$ & 0.68 & 0.47 & 0 & 1 & 1 \\
\hline$W Q I_{10} B A S E$ & 2.80 & 2.15 & 0.1 & 2.5 & 10 \\
\hline ESTUARY & 0.27 & 0.44 & 0 & 0 & 1 \\
\hline LOCAL_FWATER & 0.43 & 0.50 & 0 & 0 & 1 \\
\hline MIDWEST & 0.32 & 0.46 & 0 & 0 & 1 \\
\hline SOUTH & 0.12 & 0.32 & 0 & 0 & 1 \\
\hline INCOME2000 & 50.26 & 12.34 & 37.0 & 48.9 & 120.7 \\
\hline INCOME_APPROX & 0.26 & 0.44 & 0 & 0 & 1 \\
\hline PERCENT_USER & 62.74 & 37.85 & 0 & 63 & 100 \\
\hline PUBLISHED & 0.51 & 0.50 & 0 & 1 & 1 \\
\hline$O P E N \_E N D E D$ & 0.60 & 0.49 & 0 & 1 & 1 \\
\hline RESPONSE_RATE & 58.02 & 21.42 & 14.0 & 61.7 & 86.6 \\
\hline IN_PERSON & 0.31 & 0.46 & 0 & 0 & 1 \\
\hline STUDY_YR73 & 11.63 & 6.83 & 0 & 12 & 27 \\
\hline NUM_PERSON & 266.56 & 354.13 & 7.0 & 160.0 & 1432.0 \\
\hline
\end{tabular}


a simple but useful test for whether WTP is sensitive to the spatial scope of the water quality change. The MIDWEST and SOUTH dummy variables were included to control and test for broad regional variations in water quality values.

To capture how the characteristics of the study populations affect the value estimates, we included a household income variable INCOME2000. Most studies report a measure of average or median annual income; however, in some cases, it is only available for the full study sample rather than for a specific subsample corresponding to the value estimate. When average income was not reported at all in the study, it was approximated using Census data based on the location and year of the study. The dummy variable INCOME_APPROX identifies these observations, which account for 26 percent of the value estimates in the meta-sample. Other household characteristics that may serve as explanatory variables, such as average age, education, wealth, household size, and employment status, were only sporadically reported in the selected publications, so they were not included in the meta-analysis.

The other potentially important characteristic of the study population is the level of use of the water resource in question, represented by the variable PERCENT_USER. Roughly 20 percent of the WTP values were specifically estimated for nonusers (PERCENT_USER $=0$ ) and almost 40 percent were specifically estimated for users (PERCENT_USER = 100). PERCENT_USER for the other values varies between 47 and 85 percent.

Additional variables were created to describe potentially influential study characteristics. To account for differences in the SP methods used, we included the dummy variables OPEN_ENDED and IN_PERSON. The variable RESPONSE_RATE, which was included as a general quality indicator, varies from less than 15 percent to over 85 percent, with a mean of 61 percent. ${ }^{11}$ Roughly one-half of the estimates were published in peer-reviewed outlets, which is captured by PUBLISHED. To test for a potential systematic trend in the WTP estimates, the variable STUDY_YR73 was also included which captures the year in which the survey was conducted. A large majority of the WTP estimates included in the meta-analysis are from SP surveys conducted in the 1980 s.

\section{Meta-regression models}

Table 5 reports regression results for several model specifications, all of which share the same basic structure. We included a measure of WTP in all models as the dependent variable. Changes in water quality, as measured by the $\mathrm{WQI}_{10}$, were included in each regression. Additional explanatory variables include descriptors of the affected waters, study populations, study design, and publication outlet. To evaluate the robustness of model results, we varied the functional form across specifications, but we used a similar weighted regression and panel data estimation approach in each case.

\subsection{Functional form specification}

Results for three functional form specifications are reported in Table 5-linear, semi-log, and log-linear. ${ }^{12}$ Although all three of these forms are reasonable for approximating the relationship

\footnotetext{
${ }^{11}$ Response rates were not reported for 13 of the 131 estimates, in which case they were assigned the mean value of the other 83 estimates.

${ }^{12}$ The log-linear specification converts the dependent variable (WTP2000) and the water quality change and income terms into logarithmic form, but leaves the other (mostly dichotomous) variables in linear form.
} 
Table 5

Meta-regression results (weighted least squares; $N_{\mathrm{v}}=131$ )

\begin{tabular}{|c|c|c|c|c|c|c|c|c|c|c|c|c|}
\hline \multirow[b]{4}{*}{ Explanatory variables } & \multicolumn{12}{|c|}{ Model specification } \\
\hline & \multicolumn{4}{|l|}{ Linear } & \multicolumn{4}{|l|}{ Semi-log } & \multicolumn{4}{|l|}{ Log-linear } \\
\hline & \multicolumn{4}{|c|}{ WTP2000 } & \multicolumn{4}{|c|}{$\operatorname{Ln}(\mathrm{WTP} 2000)^{\mathrm{a}}$} & \multicolumn{4}{|c|}{$\operatorname{Ln}(\mathrm{WTP} 2000)^{\mathrm{a}}$} \\
\hline & Coef. $^{b}$ & $t^{\mathrm{c}}$ & Coef. $^{b}$ & $t^{\mathrm{c}}$ & Coef. $^{b}$ & $t^{\mathrm{c}}$ & Coef. $^{b}$ & $t^{\mathrm{c}}$ & Coef. & $t^{\mathrm{b}}$ & Coef. & $t^{\mathrm{b}}$ \\
\hline WQI ${ }_{10} C H A N G E$ & 7.21 & 1.48 & 4.44 & 0.94 & $0.145^{*}$ & 1.95 & 0.109 & 1.39 & & & & \\
\hline$W Q I_{10} C H A N G E \times W Q \_R E C \_U S E$ & 6.84 & 1.45 & $10.39^{* *}$ & 2.49 & 0.112 & 1.73 & $0.137^{* *}$ & 2.26 & & & & \\
\hline $\operatorname{Ln}\left(W Q I_{10} C H A N G E\right)$ & & & & & & & & & 0.343 & 1.20 & 0.358 & 1.37 \\
\hline$L n\left(W Q I_{10} C H A N G E\right) \times W Q \_R E C \_U S E$ & & & & & & & & & $0.414^{*}$ & 1.90 & $0.465^{* *}$ & 2.65 \\
\hline$W Q I_{10} B A S E$ & 2.49 & 0.95 & 1.93 & 0.90 & $0.113^{*}$ & 1.78 & 0.085 & 1.45 & 0.091 & 1.43 & 0.080 & 1.37 \\
\hline ESTUARY & 20.09 & 0.57 & & & 0.031 & 0.10 & & & 0.025 & 0.08 & & \\
\hline LOCAL_FWATER & -12.70 & -0.51 & & & -0.067 & -0.24 & & & -0.110 & -0.38 & & \\
\hline MIDWEST & 27.33 & 0.93 & & & 0.520 & 1.66 & & & 0.329 & 1.12 & & \\
\hline SOUTH & 7.97 & 0.31 & & & 0.148 & 0.47 & & & -0.052 & -0.16 & & \\
\hline INCOME2000 & $1.30^{* *}$ & 2.25 & $1.29^{* *}$ & 2.40 & 0.014 & 1.75 & 0.012 & 1.57 & & & & \\
\hline$I N C O M E 2000 \times I N C O M E \_A P P R O X$ & -0.44 & -1.05 & & & -0.001 & -0.25 & & & & & & \\
\hline $\operatorname{Ln}(I N C O M E 2000)$ & & & & & & & & & $0.964^{*}$ & 1.85 & $0.897^{*}$ & 1.85 \\
\hline $\operatorname{Ln}(I N C O M E 2000) \times I N C O M E \_A P P R O X$ & & & & & & & & & -0.008 & -0.11 & & \\
\hline PERCENT_USER & $0.51^{* *}$ & 4.49 & $0.55^{* *}$ & 4.62 & $0.011^{* *}$ & 9.58 & $0.011^{* *}$ & 7.80 & $0.011^{* *}$ & 9.81 & $0.011^{* *}$ & 7.85 \\
\hline PUBLISHED & $61.75^{* *}$ & 2.25 & $58.94^{* * *}$ & 2.71 & $0.971^{* *}$ & 4.07 & $0.845^{* *}$ & 3.76 & $0.960^{* * *}$ & 4.08 & $0.898^{* *}$ & 3.98 \\
\hline$O P E N \_E N D E D$ & -4.39 & -0.31 & & & 0.054 & 0.29 & & & 0.051 & 0.25 & & \\
\hline RESPONSE_RATE & -1.03 & -1.30 & $-1.32^{* *}$ & -2.73 & -0.014 & -1.35 & -0.012 & -1.60 & -0.014 & -1.26 & $-0.013^{*}$ & -1.86 \\
\hline IN_PERSON & 36.15 & 1.26 & $46.04^{*}$ & 1.95 & 0.460 & 1.33 & $0.499^{*}$ & 1.90 & 0.315 & 0.77 & 0.430 & 1.65 \\
\hline STUDY_YR73 & $-2.96^{* *}$ & -2.11 & $-2.83^{* *}$ & -3.26 & $-0.041^{* * *}$ & -2.34 & $-0.027^{* *}$ & -3.64 & $-0.041^{* *}$ & -2.49 & $-0.029^{* *}$ & -3.74 \\
\hline CONSTANT & 11.16 & 0.19 & 28.55 & 0.54 & $2.392^{* *}$ & 3.06 & $2.631^{* *}$ & 3.66 & -0.399 & -0.20 & -0.227 & -0.13 \\
\hline$R^{2}$ & 0.60 & & 0.57 & & 0.64 & & 0.61 & & 0.64 & & 0.59 & \\
\hline$p$-Value for restricted model ${ }^{\mathrm{d}}$ & & & 0.93 & & & & 0.47 & & & & 0.60 & \\
\hline
\end{tabular}

\footnotetext{
${ }^{\mathrm{a}}$ Dependent variable.

b Level of statistical significance represented by: ${ }^{*} p=0.10$ and ${ }^{* *} p=0.05$.

${ }^{c}$ Based on Huber-White robust standard errors with clustering by study ( $N_{\mathrm{s}}=18$ studies).

${ }^{\mathrm{d}} F$-test of joint restriction that coefficients of excluded variables are equal to zero.
} 
between WTP and the other variables, the log-linear approach has at least two conceptual advantages. First, it implies that, as changes in water quality approach zero, WTP also approaches zero. Second, it implies that the marginal effect of a water quality change on WTP depends on income. The semi-log model shares this second advantage; however, it also implies that if WTP increases with larger improvements in water quality, then it does so at an increasing rate (positive second derivative). ${ }^{13}$

\subsection{Regression weights}

Two weighting factors were combined in the analysis. First, treating each value estimate equally in the meta-regression is not statistically efficient because it fails to account for the fact that some values are estimated with relatively more precision than others and therefore contribute more information to the analysis. To maximize statistical efficiency of the meta-analysis, each estimate would ideally be weighted by the inverse of its variance (Lipsey and Wilson, 2000; Hedges and Olkin, 1985). Unfortunately, relatively few of the included studies report standard errors or confidence intervals for their WTP estimates. As an approximation of these relative weights, we instead weighted each (secondary) observation in direct proportion to its sample size (NUM_PERSON in Tables 3 and 4).

Second, the meta-data set contains some value estimates that are measured for the same water quality change and sample population (but, for example, using a different WTP estimation method). ${ }^{14}$ Failing to account for this feature would effectively allow publications with more reported values of this type to exert a disproportionate influence on the overall statistical results (Mrozek and Taylor, 2002). To address this issue, a second variable (INVGRPNUM) was created, which is the inverse of the number of estimates in this type of group. INVGRPNUM equals 0.5 for 51 percent of the meta-sample and 1 for the rest. All regression results reported in Table 5 were estimated using a combined weighting factor, equal to the product of NUM_PERSON and INVGRPNUM. $^{15}$

\subsection{Panel data modeling}

To account for the panel nature of the meta-data, we estimated all of the models using clustered robust regression (Rogers, 1993). Because the data used in the analysis are characterized by multiple observations from individual studies, they are likely to violate the ordinary least squares assumptions of independent and identically distributed errors. Therefore, we used the Huber-White method to correct the standard error estimates for potential error correlation within study clusters and unequal variance of errors across clusters (Williams, 2000; Froot, 1989). Alternative approaches to modeling the panel data were also explored. For example, following Rosenberger and Loomis (2000), we evaluated fixed and random effect models. Because several of the explanatory variables included in our analysis only vary across

\footnotetext{
${ }^{13}$ Box-Cox transformed models were also run for the models reported in Table 6 ; however, the specification tests were not conclusive regarding functional form.

${ }^{14}$ Note that if, in a particular study, a formal specification test shows that one value estimate is statistically superior to another, then only the superior estimate is included in the value data set.

${ }^{15}$ Sensitivity analyses of the meta-regression results to the selected weights revealed that the results (reported with weights in Table 5) were more sensitive to the inclusion of NUM_PERSON than to INVGRPNUM; however, even when neither weight was used, the regression results did not change substantially.
} 
(not within) study clusters, it was not feasible to effectively distinguish between these factors and study level fixed effects. Moreover, 18 fixed effects dummies would cause degrees of freedom problems in a 131 observation data set. However, we were able to estimate random effects models using the regression specifications reported in Table 5. The regression results were not appreciably different from those reported in Table 5, but Breusch-Pagan tests consistently rejected the random effects model in favor of the models without random effects. ${ }^{16}$

\section{Meta-regression results}

Table 5 reports results for six meta-regression equations. For each of the three functional forms - linear, semi-log, and log-linear - two similar model specifications are reported. The first is a full model with all of the main explanatory variables included, while the second is a restricted model using a more parsimonious specification.

The models all provide a reasonably good fit to the data, with $R$-squared statistics between 0.57 and 0.64 . The sign and statistical significance of the explanatory variables are relatively consistent across the linear, semi-log, and log-linear specifications. The restricted models exclude variables that are not individually significant at 0.10 level or less (based on $t$-statistics). In all three cases, the dropped variables include ESTUARY, LOCAL_FWATER, MIDWEST, SOUTH, OPEN_ENDED, and the interacted variable for INCOME2000 and INCOME_APPROX. In all three cases, these restrictions cannot be rejected at a 0.05 level using an $F$-test. Due to their conceptual and economic importance in the model, all water quality variables are retained in the restricted models regardless of their statistical significance. The variables RESPONSE_RATE and IN_PERSON are also retained because restricted models excluding these variables can be rejected at a 0.05 level.

Most importantly, the results indicate that the WTP estimates are sensitive to scope when water quality changes are characterized using recreational use descriptions (which is the case in over two-thirds of the WTP observations). Although the coefficient for $\mathrm{WQI}_{10} \mathrm{CHANGE}$ (and its $\log$ form) is not statistically significant, the combined effect of $\mathrm{WQI}_{10} \mathrm{CHANGE}$ and the interacted term $\mathrm{WQI}_{10} \mathrm{CHANGE} \times$ WQ_REC_USE is always positive and statistically different from zero at a 0.05 level. In the restricted models, the interacted variable is also individually significant. This result indicates that the effect of water quality change on WTP is significantly greater when water quality changes are characterized using recreational use descriptions. The results of the linear specifications suggest that each unit increase on the $\mathrm{WQI}_{10}$ scale that includes a recreational use description increases WTP by an average $\$ 14$. The log-linear models indicate an increase of about 8 percent in WTP for each 10 percent increase in the water quality scale. The analysis also finds that WTP for water quality improvements is not strongly associated with baseline water quality levels. The coefficient for $\mathrm{WQI}_{10} \mathrm{BASE}$ is estimated to be positive but is only statistically significant at a 0.10 level in the restricted semi-log specification. The WTP estimates also show limited sensitivity to the spatial scope of the change in water quality. The coefficient for LOCAL_FWATER is consistently negative but not statistically significant.

Characteristics of the study population are also found to influence WTP. PERCENT_USER has a consistently positive and significant effect on WTP across all specifications. According to results in the linear (log-linear) specification, users are on average willing to pay roughly $\$ 60$

\footnotetext{
${ }^{16}$ Other methods for clustering the data were also explored, such as using the 21 publications as clusters instead of the 18 studies, but the regression results were found to be relatively insensitive to these alternatives.
} 
(three times) more than nonusers for improvements in freshwater quality. ${ }^{17}$ This estimated ratio between use and nonuse values is similar, but somewhat larger, than the results reported by Johnston et al. (2003). ${ }^{18}$

In accordance with expectations, the sign of the main income effect is also consistently positive and for the most part statistically significant across specifications. Moreover, in the log-linear models, the size of the income elasticity is very close to 1 . The interaction of income with the income approximation dummy variable is consistently negative but not statistically significant.

The variables IN_PERSON and RESPONSE_RATE are both statistically significant at a 0.10 level in two of the three restricted models. The effect of IN_PERSON on WTP is found to be positive in all cases, which is consistent with the hypothesis that in-person interviews encourage yea-saying by respondents. The effect of RESPONSE_RATE is negative in all models. Although there are no strong priors for how response rates should affect the magnitude of WTP estimates, these results suggest that surveys with lower response rates tend to exclude individuals with lower average WTP for water quality improvements.

The only other variables found to have statistically significant effects on WTP are PUBLISHED and STUDY_YR73. In contrast to the findings discussed in Rosenberger and Stanley (2006), PUBLISHED has a large, positive and significant coefficient estimate in all 6 specifications. Results from the log-linear model indicate that values from published studies are higher by a factor of roughly 2.5. ${ }^{19}$ One interpretation of this result is that publication is an indicator of study quality, and therefore higher quality studies tend to produce higher WTP estimates. However, if PUBLISHED is interpreted as a filter that favors larger, statistically significant values, then this result suggests the presence of publication bias. The negative effect of STUDY_YR73 indicates that, controlling for income and price effects, estimates of average real WTP for water quality improvements has declined over time at roughly 2-3 percent per year. It is possible that this decline reflects changes in preferences over time; however, it may also be the result of other factors, such as possible changes in publication selection processes (e.g., by authors or editors) or in estimation methods, that tend to favor lower WTP estimates.

\section{Implications for benefits transfer and policy analysis}

In a recent summary and evaluation of meta-analysis applications in nonmarket valuation, Smith and Pattanayak (2002) argue that meta-analyses in this field have generally served three main purposes: research synthesis, hypothesis testing, and prediction. The previous sections of this paper have addressed the first two objectives, while this section addresses the third objective by exploring the implications of the meta-regression results for predicting WTP. A main purpose of WTP prediction is to support policy analysis. It allows one to evaluate the benefits of policy related changes in water quality by transferring estimates that are based on the existing valuation literature. A key issue, though, is whether the estimated equations can provide reliable benefit transfer functions for predicting WTP for specified water quality changes.

To explore and illustrate the implications of the meta-regression results for benefit transfer, we chose the linear and log-linear specifications as benefit transfer functions and used them to

\footnotetext{
${ }^{17}$ Measured as the effect on WTP of going from PERCENT_USER $=0$ to PERCENT_USER $=100$.

${ }^{18}$ Evaluated at the mean of their sample of nonuse estimates, Johnston et al. estimated that nonuse values increase by roughly $\$ 1$ for each $\$ 2$ increment in use values for water quality improvements.

${ }^{19}$ Percent change calculated from the coefficients $(\beta$ 's) using the formula $\exp (\beta)-1$ (Halvoreson and Palmquist, 1980).
} 
Table 6

Predicted mean annual WTP for selected water quality improvement scenarios using alternative model specifications

\begin{tabular}{|c|c|c|c|c|}
\hline \multirow[t]{2}{*}{ Water quality improvement } & \multicolumn{2}{|l|}{ Users } & \multicolumn{2}{|l|}{ Nonusers } \\
\hline & Full model & Restricted model & Full model & Restricted model \\
\hline \multicolumn{5}{|l|}{ Linear transfer functions ${ }^{\mathrm{a}}$} \\
\hline$W Q I_{10} C H A N G E=1$ & $\$ 56(-\$ 1-112)$ & $\$ 58(\$ 56-142)$ & $\$ 5(-\$ 57-67)$ & $\$ 3(-\$ 45-50)$ \\
\hline$W Q I_{10} C H A N G E=3$ & $\$ 84(\$ 32-136)$ & $\$ 87(\$ 87-164)$ & $\$ 33(-\$ 26-92)$ & $\$ 32(-\$ 7-72)$ \\
\hline$W Q I_{10} C H A N G E=6$ & $\$ 126(\$ 71-181)$ & $\$ 132(\$ 135-244)$ & $\$ 75(\$ 13-138)$ & $\$ 77(\$ 30-124)$ \\
\hline \multicolumn{5}{|l|}{ Log-linear transfer functions ${ }^{b}$} \\
\hline$W Q I_{10} C H A N G E=1$ & $\$ 32(\$ 5-60)$ & $\$ 37(\$ 16-60)$ & $\$ 11(\$ 1-21)$ & $\$ 13(\$ 0.4-44)$ \\
\hline$W Q I_{10} C H A N G E=3$ & $\$ 74(\$ 26-122)$ & $\$ 93(\$ 65-120)$ & $\$ 24(\$ 8-40)$ & $\$ 31(\$ 9-77)$ \\
\hline$W Q I_{10} C H A N G E=6$ & $\$ 125(\$ 37-213)$ & $\$ 164(\$ 94-234)$ & $\$ 41(\$ 14-68)$ & $\$ 55(\$ 23-131)$ \\
\hline
\end{tabular}

a $95 \%$ confidence intervals estimated using STDP command in STATA.

b $95 \%$ confidence intervals estimated using asymptotic standard errors.

predict WTP for selected scenarios. For these two specifications, we selected both the full and restricted models from Table 5.

The predicted mean WTP estimates (and corresponding 95\% confidence intervals) are reported in Table 6. As shown in the table, we specified three different changes in freshwater quality levels $\left(1,3\right.$, and 6 unit changes on the $\left.\mathrm{WQI}_{10}\right)$ in each case assuming WQ_REC_USE equals 1. Using the four functions, we then separately predicted mean WTP for users and nonusers. For all WTP predictions, income was set at average U.S. household income in 2003 ( $\$ 55,280$ in 2000 dollars), PUBLISHED was set at 0.5 (due to the uncertainties regarding whether this variable reflects study quality or publication bias) and the study year was assumed to be 2003. All other variables were set at their sample means.

With the linear function, the predicted mean WTP estimates for a one-unit change in water quality varies from $\$ 3-5$ for nonusers to $\$ 56-58$ for users. For a six-unit change, the predicted values are all greater by $\$ 70-74$. For all water quality changes, the difference between estimates for users and nonusers is $\$ 51-55$. The invariance of this difference with respect to the size of the water quality change is one of the inherent limitations of the linear model as a benefit transfer function.

With the log-linear function, the predicted mean WTP estimates for a one-unit change in water quality varies from $\$ 11-13$ for nonusers to $\$ 32-37$ for users. ${ }^{20}$ For a six-unit change, the predicted values are all greater by a factor of roughly 4 . The WTP estimates for users are greater than for nonusers by a factor of 3 .

To further evaluate these meta-regression equations as benefit transfer functions, it is useful to also compare the results with estimates based on other benefit transfer approaches. Perhaps the most commonly used and cited benefit estimates for national water quality changes come from Carson and Mitchell (CM, 1993), which is one of the studies (three value estimates) included in our metaanalysis. Based on a nationwide CV survey conducted in the early 1980s, this study presented respondents with national water quality increments (e.g., boatable-to-fishable and fishable-toswimmable) that were mapped to the WQL. Using results from their sample of 564 households,

\footnotetext{
${ }^{20}$ To appropriately transform the model prediction of mean $\ln (\mathrm{WTP})$ to mean WTP in nonlogarithmic form, we applied a smearing factor to the model-predicted values (Duan, 1983). The smearing factor is equal to the average of the exponentiated residuals for the 131 observations in the estimation sample.
} 
they estimated a WTP function with respect to the water quality scale, household income, household participation in freshwater recreation, and the respondent's rating of the importance of national water protection goals. Applying this function using: (1) average U.S. household income in 2003 (\$55,280 in 2000 dollars) and (2) sample averages from CM for freshwater recreation participation (59 percent) and importance rating (0.65), their data and model would predict WTP for the boatable-to-fishable and fishable-to-swimmable increments to be $\$ 181$ and $\$ 132$, respectively (in 2000 dollars). For similar increments in water quality (2.5 points for the boatableto-fishable increment and 2 points for the fishable-to-swimmable increment), our parsimonious linear meta-regression equation predicts annual average WTP of $\$ 111(95 \%$ C.I. $=\$ 89-132)$ and $\$ 113$ (95\% C.I. $=\$ 92-134)$, respectively (for PCT_USER $=59$ and INCOME2000 = 55.28). Our log-linear equation predicts WTP of $\$ 91(95 \%$ C.I. $=\$ 67-114)$ and $\$ 89(95 \%$ C.I. $=\$ 63-116)$, respectively. Therefore, for the fishable-to-swimmable increment, the linear meta-regression equation generates estimates that are similar to the CM transfer function estimates. Otherwise the meta-regression equation estimates are lower by as much as 50 percent, particularly for the boatable-to-fishable increment. In contrast to the meta-regression results, the CM function predicts declining WTP with respect to baseline water quality and, therefore, substantially higher values for improvements that start from the lower baseline level of boatable water quality.

\section{Conclusions and recommendations}

The number of empirical studies applied to water quality valuation has expanded steadily since the mid-1970s. The resulting body of literature provides a potentially rich source of secondary data for evaluating national and regional water policy; however, the heterogeneity of the commodities used to define water quality presents a challenge for policy analysis. This paper explores how this literature can be used to systematically estimate the benefits of national and regional water quality changes, and identifies potential solutions to the challenges presented by its shortcomings.

Using meta-analysis, we analyze results from 18 stated preference studies conducted in the U.S. We find evidence of a systematic and theoretically consistent pattern in WTP estimates. In particular, the value estimates are positively related to the size of the water quality change-i.e., they "pass" the scope test when water quality changes are expressed using references to recreational uses. As expected, we also find that these values are systematically lower for nonusers of the affected resources, as well as evidence of a positive relationship between average WTP and average income. The goodness of fit of these regressions, as measured by the $R$-squared statistics, is also reasonable for a cross-sectional data set. ${ }^{21}$

The results of our review and analysis of water quality valuation estimates have mixed implications for national policy analysis using benefit transfer. Although the existing empirical literature in this area is extensive, only a small subset of these values could be meaningfully combined through meta-analysis. One major reason for this limitation is that water quality is defined and characterized in a variety of ways across studies.

Thus, on the one hand, our meta-regression results provide a reasonable basis for predicting how average WTP varies for broad changes in water quality, and can be used as a benefit transfer

\footnotetext{
${ }^{21} R$-square statistics from analyses of meta-data are typically higher than from cross-sectional analysis in the same way that macroeconomic regressions generally perform better than micro-economic regressions because individual heterogeneity is averaged out. The screening process (131 observations from a potential base of more than 1000 observations) has also imposed more homogeneity on the meta-data.
} 
function. On the other hand, some of the main limitations of these models as benefit transfer tools for national policy analysis are a consequence of the variation in WTP that is not explained by the meta-regressions. For example, our results provide very limited evidence about how WTP is related to the spatial characteristics of water quality changes. The meta-regression does not measure how WTP varies with respect to the proportion or amount of waters that are improved or the distance of the water quality changes from populations. This lack of specificity imposes limitations on the precision of policy-relevant benefit transfers, since policies almost always impact waterbodies in spatially nonuniform ways.

Consequently, despite the large and diverse body of existing studies, there is a continued need for water quality valuation research that can be used to address the requirements of national and regional-scale benefit assessments. The ability to integrate and apply the results of this research could be enhanced in several ways. First, a more standardized and policy-relevant approach for defining water quality changes, such as the designated use classifications used in setting water quality standards, could be applied in these studies. An example is the approach taken by Viscusi et al. (2004) and Magat et al. (2000) in which they define the extent and spatial variation in water quality in terms of the percentage of waters within 100 miles of a person's home that is "good" (i.e., unimpaired) for three designated uses-primary contact recreation (safe to swim), fish consumption (safe to eat fish), and aquatic life (aquatic ecosystem is healthy). Because state and federal water quality standards are steadily adopting these use-based designations, this approach is more directly policy relevant. Table 7 lists eight "designated use" categories that are increasingly being applied in setting such water quality standards. In contrast to the WQL approach, which focuses on recreational uses in its terminology (boating, fishing, swimming), use-specific water quality standards define more dimensions of water quality, which, as shown in Table 7, can be linked with various categories of water-based ecosystem services. In addition to being policy relevant, an important advantage of this use-based definition of water quality is that it is directly linkable to chemical, physical, and biological indicators of water quality through federal and state ambient water quality standards and criteria. This would then make it possible to systematically consider the relationship between water quality indicators (inputs) and the services produced by ecosystems.

Table 7

Relationship between water quality services (designated use categories) and sources of economic value

\begin{tabular}{|c|c|c|c|c|c|}
\hline \multirow{3}{*}{$\begin{array}{l}\text { Water quality services } \\
\text { (i.e., designated use category) }\end{array}$} & \multicolumn{5}{|c|}{ Economic value for water quality improvements derived from ... } \\
\hline & \multicolumn{3}{|c|}{ Use related services ... } & \multicolumn{2}{|l|}{ Nonuse services ... } \\
\hline & $\begin{array}{l}\text { In market } \\
\text { production }\end{array}$ & $\begin{array}{l}\text { In household } \\
\text { production }\end{array}$ & $\begin{array}{l}\text { In public } \\
\text { sector } \\
\text { production }\end{array}$ & $\begin{array}{l}\text { Related to } \\
\text { existence/intrinsic } \\
\text { values }\end{array}$ & $\begin{array}{l}\text { From altruism } \\
\text { and bequest } \\
\text { motives }\end{array}$ \\
\hline $\begin{array}{l}\text { Primary contact recreation } \\
\text { (safe to swim) }\end{array}$ & & & & & \\
\hline $\begin{array}{l}\text { Secondary contact recreation } \\
\text { (safe to fish, boat) }\end{array}$ & & & & & \\
\hline $\begin{array}{l}\mathrm{Ag} \text { water supply } \\
\quad \text { (irrigation and livestock) }\end{array}$ & 0 & & & & \\
\hline Industrial water supply & 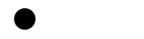 & & & & \\
\hline Public water supply & & & & & \\
\hline Aesthetics (visibility, odor) & 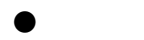 & 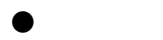 & & & \\
\hline Fish consumption (safe to eat fish) & 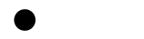 & 0 & & & \\
\hline Aquatic life (cold and warm water) & & & & O & \\
\hline
\end{tabular}


Second, national and regional policy analysis would benefit from water quality valuation research conducted: (1) on a larger geographic scale and (2) in parts of the country that are currently not well represented in the literature. As shown in Table 1, relatively few studies have addressed water quality changes that occur over more than one state, and even fewer have specifically investigated the sensitivity of WTP with respect to the geographic extent of the water quality change or the distance of the water quality change from an individual's residence. As also shown in Table 1, few studies have been conducted for water quality changes in the western portion of the United States. Additional studies in these areas would help to address important spatial gaps in the literature.

Third, greater detail and consistency in the type of information reported in published water quality valuation studies would enhance the social utility of the empirical literature. In particular, more detailed characterizations of the studied water resources and affected populations would be beneficial. Ideally, these descriptions would include pre-change and post-change water quality, and information on the spatial and temporal variation in water quality, physical characteristics and typical uses (including designated uses) of the water resources. They would also include types and levels of use of the water resource (e.g., average number of trips), and average travel distance to the affected resources. With a larger number of well-defined and well-documented value estimates for water quality changes across the country, it should be possible to perform a more comprehensive assessment (including via meta-analyses) that can lead to more definitive conclusions for policy analysis.

\section{Acknowledgements}

Financial support for this research was provided by the U.S. Environmental Protection Agency under Contract 68-C-01-142. Thanks are due to Mahesh Podar, Melonie Sullivan, Chris Dockins, Julie Hewitt, Ghulam Ali, Craig Landry, Kerry Smith, John Whitehead, and two anonymous referees for their helpful comments and suggestions. We also acknowledge research assistance provided by Jui-Chen Yang and Charles Pringle. Any opinions, findings, conclusions, or recommendations expressed in this paper are those of the authors and do not necessarily reflect the views of the U.S. EPA.

\section{References}

Azevedo, C., Herriges, J., Kling, C., 2001. Valuing Preservation and Improvements of Water Quality in Clear Lake. Working Paper, Center for Agricultural and Rural Development, Iowa State University.

Binkley, C.S., Hanemann, W.M., 1978. The Recreation Benefits of Water Quality Improvement: Analysis of Day Trips in an Urban Setting. U.S. EPA Report, EPA-600/5-78-010. EPA, Office of Health and Ecological Effects, Washington, DC.

Bockstael, N.E., Hanemann, W.M., Kling, C.L., 1987. Estimating the value of water quality improvements in a recreational demand framework. Water Resources Research 23 (5), 951-960.

Bockstael, N.E., McConnell, K.E., Strand, I.E., 1989. Measuring the benefits of improvements in water quality: the Chesapeake Bay. Marine Resource Economics 6, 1-18.

Boyer, T., Polasky, S., 2004. Valuing Urban Wetlands: A Review of Non-Market Valuation Studies. Working Paper. Available at: http://www.apec.umn.edu/faculty/spolasky/ValuingUrbanWetlands.pdf.

Carson, R.T., 2000. Contingent valuation: a user's guide. Environmental Science and Technology 34, $1413-1418$.

Carson, R.T., Mitchell, R.C., 1993. The value of clean water: the public's willingness to pay for boatable, fishable, and swimmable quality water. Water Resources Research 29 (7), 2445-2454.

Croke, K., Fabian, R., Brenniman, G., 1986. Estimating the value of improved water quality in an urban river system. Journal of Environmental Systems 16 (1), 13-23. 
Cronin, F.J., 1982. Valuing Nonmarket Goods Through Contingent Markets. Pacific Northwest Laboratory, PNL-4255, Richland, WA.

Desvousges, W.H., Smith, V.K., Fisher, A., 1987. Option price estimates for water quality improvements: a contingent valuation study for the Monongahela River. Journal of Environmental Economics and Management 14, 248267.

Duan, N., 1983. Smearing estimate: a nonparametric retransformation method. Journal of the American Statistical Association 78 (383), 605-610.

Edwards, S.F., 1984. An Analysis of the Non-Market Benefits of Protecting Salt Pond Water Quality in Southern Rhode Island: An Application of the Hedonic Price and Contingent Valuation Techniques. PhD Dissertation, University of Rhode Island.

Farber, S., Griner, B., 2000. Valuing watershed quality improvements using conjoint analysis. Ecological Economics 34 , 63-76.

Froot, K.A., 1989. Consistent covariance matrix estimation with cross-sectional dependence and heteroskedasticity in financial data. Journal of Financial and Quantitative Analysis 24, 333-355.

Gramlich, F.W., 1977. The demand for clean water: the case of the Charles River. National Tax Journal 30 (2), $183-$ 194.

Halvoreson, R., Palmquist, R., 1980. The interpretation of dummy variables in semilogarithmic equations. American Economic Review 70 (3), 474-475.

Hayes, K.M., 1987. An Analysis of Improving Water Quality in Narragansett Bay: An Application of the Contingent Valuation Method. Masters Thesis, Department of Resource Economics, University of Rhode Island.

Hayes, K.M., Tyrrell, T., Anderson, G., 1992. Estimating the benefits of water quality improvements in the Upper Narragansett Bay. Marine Resource Economics 7 (1), 75-85.

Hedges, L.V., Olkin, I., 1985. Statistical Methods for Meta-Analysis. Academic Press, New York.

Johnston, R.J., Besedin, E.Y., Wardwell, R.F., 2003. Modeling relationships between use and nonuse values for surface water quality: a meta-analysis. Water Resources Research 39 (12), WES2-1-WES2-9.

Johnston, R.J., Besedin, E.Y., Iovanna, R., Miller, C.J., Wardwell, R.F., Ransom, M.H., 2005. Systematic variation in willingness to pay for aquatic resource improvements and implications for benefit transfer: a meta-analysis. Canadian Journal of Agricultural Economics 53, 221-248.

Johnston, R.J., Swallow, S.K., Weaver, T.F., 1999. Estimating willingness to pay and resource tradeoffs with different payment to mechanisms: an evaluation of a funding guarantee for watershed management. Journal of Environmental Economics and Management 38, 97-120.

Kaoru, Y., 1993. Differentiating use and non-use values for coastal pond water quality improvements. Environmental and Resource Economics 3, 487-494.

Lant, C.L., Roberts, R.S., 1990. Greenbelts in the Cornbelt: riparian wetlands, intrinsic values and market failure. Environment and Planning 22, 1375-1388.

Lant, C.L., Tobin, G.A., 1989. The economic value of riparian corridors in Cornbelt floodplains: a research framework. Professional Geographer 42 (3), 337-349.

Lipsey, M.W., Wilson, D.B., 2000. Practical meta-analysis. Applied Social Science Research Methods Series, vol. 49. Sage Publications, Thousand Oaks, CA.

Lipton, D., 2003. The Value of Improved Water Quality to Chesapeake Bay Boaters. Working Paper WP 03-16, Department of Agricultural and Resource Economics, University of Maryland, College Park.

Loomis, J., White, D., 1996. Economic benefits of rare and endangered species. Ecological Economics 18, $197-206$.

Magat, W.A., Huber, J., Viscusi, W.K., Bell, J., 2000. An iterative choice approach to valuing clean lakes, rivers, and streams. Journal of Risk and Uncertainty 21 (1), 7-43.

McClelland, N.I., 1974. Water Quality Index Application in the Kansas River Basin. Prepared for the U.S. Environmental Protection Agency-Region 7 (EPA-907/9-74-001).

McConnell, K.E., 1990. Models for referendum data: the structure of discrete choice models for contingent valuation. Journal of Environmental Economics and Management 18 (January), 19-34.

McConnell, V., Walls, M., 2005. The Value of Open Space: Evidence from Studies of Nonmarket Benefits. RFF Report. Available at: http://www.rff.org/rff/Documents/RFF-REPORT-Open\%20Spaces.pdf.

Mitchell, R.C., Carson, R.T., 1986. The Use of Contingent Valuation Data for Benefit Cost Analysis in Water Pollution Control. Report to U.S. Environmental Protection Agency, Resources for the Future (September).

Mrozek, J., Taylor, L., 2002. What determines the value of life? a meta analysis. Journal of Policy Analysis and Management 21 (2), 253-270.

NRC/NAS, 2005. Valuing Ecosystem Services: Toward Better Environmental Decision-Making. National Academies Press, Washington, DC. 
Nowak, P.J., Petchenik, J.B., Carman, D.M., Nelson, E.B., 1989. Water Quality in the City of West Bend, the Citizen's Perspective. Submitted to the Wisconsin Department of Natural Resources and the Milwaukee River Basin Citizen Advisory Committee.

Nowak, P.J., Petchenik, J.B., Carman, D.M., Nelson, E.B., 1990. Water Quality in the Milwaukee Metropolitan Area, the Citizen's Perspective. Submitted to the Wisconsin Department of Natural Resources and the Milwaukee River Basin Citizen Advisory Committee.

Nunes, P.A.L.D., Van Den Bergh, J.C.J.M., Nijkamp, P., 2001. Ecological-Economic Analysis and Valuation of Biodiversity. FEEM Working Paper No. 74.2001.

Poe, G.L., Boyle, K.J., Bergstrom, J.C., 2001. A preliminary meta analysis of contingent values for ground water quality revisited. In: Bergstrom, J.C., Boyle, K.J., Poe, G.L. (Eds.), The Economic Value of Water Quality. Edward Elgar, Northampton, MA.

Rosenberger, R.S., Loomis, J.B., 2000. Panel stratification in meta-analysis of economic studies: an investigation of its effects in the recreation valuation literature. Journal of Agricultural and Applied Economics 32 (3), 459-470.

Rosenberger, R.S., Stanley, T.D., 2006. Measurement, generalization, and publication: sources of error in benefit transfers and their management. Ecological Economics 60, 372-378.

Rogers, W.H., 1993. Regression standard errors in clustered samples. Stata Technical Bulletin 13, 19-23 (Reprinted in Stata Technical Bulletin Reprints 3, 88-94).

Smith, R.D., 2000. The discrete-choice willingness-to-pay question format in health economics: should we adopt environmental guidelines? Medical Decision Making 20, 194-206.

Smith, V.K., Desvousges, W.H., 1986. Measuring Water Quality Benefits. Kluwer-Nijhoff, Boston.

Smith, V.K., Pattanayak, S.K., 2002. Is meta-analysis the Noah's Ark for non market valuation? Environmental and Resource Economics 22 (1-2), 271-296.

Stanley, T.D., 2001. Wheat from chaff: meta-analysis as quantitative literature review. The Journal of Economic Perspectives 15 (Summer), 131-150.

Vaughan, W.J., 1986. The Water Quality Ladder. Included as Appendix B in Mitchell, R.C., Carson, R.T., 1986. The Use of Contingent Valuation Data for Benefit/Cost Analysis in Water Pollution Control. CR-810224-02. Prepared for U.S. Environmental Protection Agency, Office of Policy, Planning, and Evaluation, Washington, DC.

Viscusi, W.K., Huber, J., Bell, J., 2004. The Value of Regional Water Quality Improvements. Harvard John M. Olin Center Discussion Paper No. 477.

Walsh, R.G., Greenley, D.A., Young, R.A., McKean, J.R., Prato, A.A., 1978. Option Values, Preservation Values and Recreational Water Quality: A Case Study of the South Platte River Basin, Colorado.

Wey, K., 1990. A Social Welfare Analysis of Congestion and Water Quality of Great Salt Pond, Block Island, Rhode Island. Dissertation, University of Rhode Island.

Whitehead, J.C., 1995. Willingness to pay for quality improvements: comparative statics and interpretation of contingent valuation results. Land Economics 71 (2), 207-215.

Williams, R.L., 2000. A note on robust variance estimation for cluster-correlated data. Biometrics 56, 645-646.

Woodward, R.T., Wui, Y.-S., 2001. The economic value of wetlands: a meta-analysis. Ecological Economics 37, 257-270. 